\title{
Emerging educational technologies in higher educational institutions: The current trends and impacts from Thailand universities' perspectives
}

Skonchai Chanunan ${ }^{\mathrm{a}^{*}}$

Michael Bruckner ${ }^{\mathrm{b}}$

Suggested Citation:

New Trends and Issues Proceedings on

Humanities and Social Sciences.

Abstract 
New Trends and Issues Proceedings on Humanities and Social Sciences.

1. Introduction 
Educational Technology and Society

1.1. The Technology Hype Cycle approach

Error! Reference source not found. 


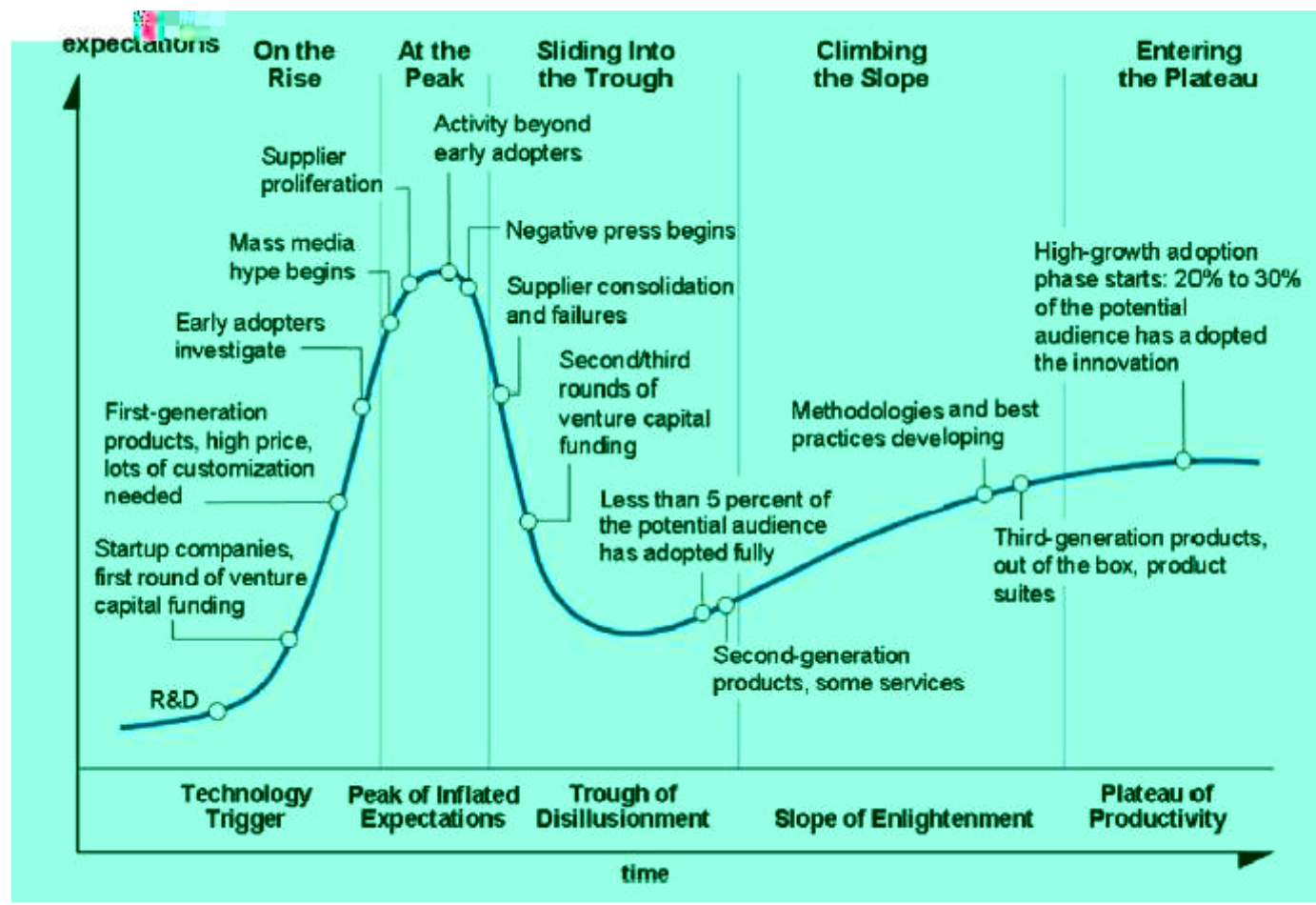

Figure 1. 2014 Hype cycle graph for emerging educational technologies (Gartner, 2014)

Table 1. Technology Hype Cycle phases and their explanation 


\section{Research Questions and Purposes}

3. Method 
New Trends and Issues Proceedings on Humanities and Social Sciences.

New Trends and Issues Proceedings on Humanities and Social Sciences. 
New Trends and Issues Proceedings on Humanities and Social Sciences.

\section{Results and Discussion}


New Trends and Issues Proceedings on Humanities and Social Sciences.

4.1. Open source learning repositories 
New Trends and Issues Proceedings on Humanities and Social Sciences.

4.2. Social learning platforms

4.3. Cloud email for staff and faculty 
New Trends and Issues Proceedings on Humanities and Social Sciences.

4.4. Emergency Mass Notification Services (EMNS) 
New Trends and Issues Proceedings on Humanities and Social Sciences.

4.6. Unified communication and collaboration technologies 
New Trends and Issues Proceedings on Humanities and Social Sciences.

\subsection{Student Retention CRM}


New Trends and Issues Proceedings on Humanities and Social Sciences.

\section{Conclusion and Recommendations}




\section{References}

18

Journal of Universal Computer Science,

Proceedings of the 16th International Conference on Information Integration and Web-based Applications \& Services

Internet and Higher Education, 15,

IEEE Frontiers in Education Conference

Learning Objects, 3,

Interdisciplinary Journal of Knowledge and

Proceedings of the 21st International Conference on World Wide Web

Hype Cycle for education

European Journal of Open, Distance and E-learning, 18

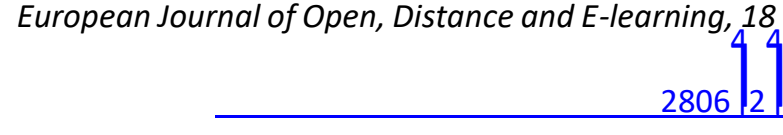

Journal

of Education and Training Studies, 2

PLE Conference Proceedings, 1

2013 higher education edition

Technological Forecasting and Social Change, 79

International Journal of Simulation, 9

Journal of Technology and Teacher Education, 9
NMC horizon report: 
Education Sciences, 5

Open Education Research, 4,

Mobile and Wireless Technology 2015

Conference (FIE), 2014 IEEE

Virtual Learning Environments
Frontiers in Education

Research Policy 44

Design, Implementation, and Evaluation of

Australasian Journal of Educational Technology, 27

HRD Journal, 5

Networking,

Architecture and Storage (NAS), 2011 6th IEEE International Conference on

Research and Development in Medical Education, 4

UNESCO World Congress releases 2012

Paris OER Declaration.

Emerging

Technologies in Distance Education

Proceedings of the 7th International Conference on Educational Data Mining (EDM 2014),

International Journal of Information Management 31 